
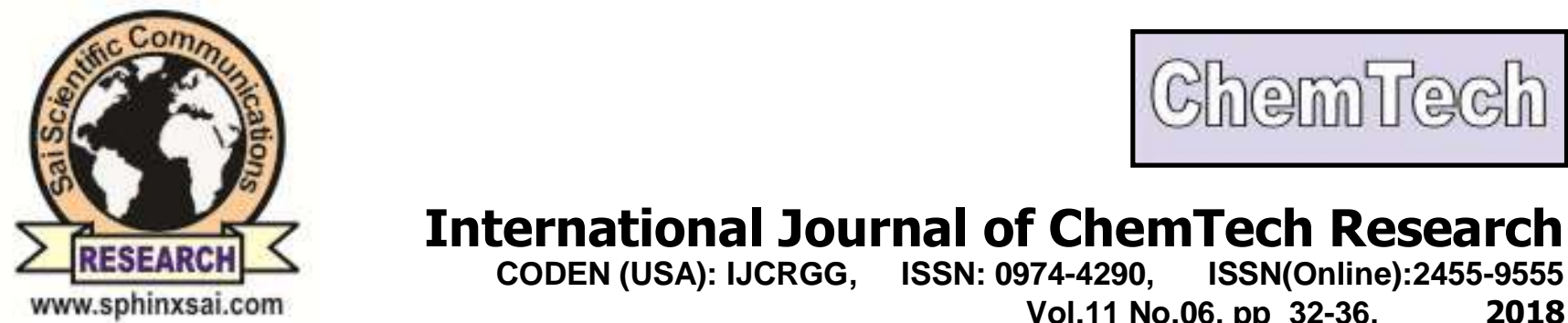

International Journal of ChemTech Research CODEN (USA): IJCRGG, ISSN: 0974-4290, ISSN(Online):2455-9555

Vol.11 No.06, pp 32-36,

2018

\title{
Relationship Knee Osteoarthritis Grade and Serum Cholesterol Level in North Sumatera
}

\author{
Rudi Hadinata $^{1 *}$, Chairiandi Siregar $^{2}$ \\ ${ }^{1}$ Resident of Orthopaedic \& Traumatology Department, Faculty of Medicine, \\ University of Sumatera Utara, Indonesia \\ ${ }^{2}$ Consultant of Orthopaedic \& Traumatology Department, Faculty of Medicine, \\ University of Sumatera Utara, Indonesia
}

\begin{abstract}
Background : Several studies have shown a clear association with obesity, age, gender and osteoarthritis, however the role of cholesterol is unclear. The aim of this study was to determine whether serum cholesterol level were associated with the grade of knee osteoarthritis.

Methods : Plasma levels of total cholesterol, triglycerides, low density lipoprotein, high density lipoprotein were measured in 47 knee osteoarthritis. Knee osteoarthritis were defined using Kellgren-Lawrence grading scale.

Results : There were 40 females $(85.1 \%)$ and 7 males $(14.9 \%)$ with a mean of age $61.38 \pm$ 10.43 years respectively. Subject with osteoarthritis correlated with gender male/female, grade I 4(0/10), grade II 11(14.3/25), grade III 14(28.6/30), grade IV 18(57.2/35) averaged 2.8 \pm 0.98 . There was no significant correlation between level of total serum cholesterol, triglycerides, low density lipoprotein, high density lipoprotein and knee osteoarthritis grade.

Conclusions : In conclusion all the lipid and lipoprotein that observed in knee osteoarthritis radiograph have no relationship with its grade.

Keywords : lipid, lipoprotein, osteoarthritis.
\end{abstract}

\section{Introduction}

Osteoarthritis (OA) is the most common joint disease worldwide, affecting $9.6 \%$ of men and $18 \%$ of women aged $>60$ years (Clockaerts, 2013). It is one of most significant musculoskeletal disorder in the western world and has become one of the common debilitating diseases in Asia and South Asia (Qureshi \& Afzal, 2014). Prevalence of knee osteoarthritis in Indonesia is quite high, about $15.5 \%$ in male and $12.7 \%$ in female from all of all patients with osteoarthritis (Mutiwara et al. 2016). Relationship of osteoarthritis with obesity, age and gender are well established risk factors of osteoarthritis. However, association between osteoarthritis and dyslipidemia is not clear. Sturmer et al found a significant independent role of hypercholesterolemia with generalized osteoarthritis (Gabay \& Kushner, 1999 ; Stone, 1994) and Chingford study suggested its significant association with both unilateral and bilateral knee osteoarthritis. However, other studies have not shown any

Rudi Hadinata et al /International Journal of ChemTech Research, 2018,11(06): 32-36. 
significant relationship between dyslipidemia and osteoarthritis. Bagge et al have found a non significant association of osteoarthrits with metabolic factors like serum cholesterol, trigycerides, and uric acid (Sturmer et al. 1998). The aim of this study was to determine whether serum cholesterol level were associated with the grade of knee osteoarthritis.

\section{Methods}

This cross sectional study was conducted at Medical Faculty of North Sumatera University / Haji Adam Malik Hospital, North Sumatera, Indonesia for the duration thirteen months from June 2016. 47 subjects with knee osteoarthritis who had met the Kellgren-Lawrence criteria were graded. Blood samples were obtained for the lipid profiles including the levels of total serum cholesterol, low density lipoprotein cholesterol, high density lipoprotein cholesterol, and triglyceride were measured in all subjects.

Correlation test was used to find out the relationship of knee osteoarthritis grade and serum cholesterol level. The relation between knee osteoarthritis grade and serum cholesterol level were analysed using a Spearman Rho correlation coefficient. All statistical calculation were performed using computer based statistic programme. The study approved by the Health Research Ethical Committee of Medical Faculty of North Sumatera University / Haji Adam Malik Hospital and an Informed consent was obtained from all subjects.

\section{Results}

The study included 47 knee osteoarthritis patients, $14.9 \%(n=7)$ in men and $85.1 \%(n=40)$ in women with a mean age of $61.38 \pm 10.43$ years respectively. Subject with osteoarthritis correlated with gender male/female, grade I 4(0/10), grade II 11(14.3/25), grade III 14(28.6/30), grade IV 18(57.2/35), the mean Kellgren-Lawrence score of the knee $\mathrm{x}$-rays of the patients with knee osteoarthritis was $2.8 \pm 0.98$.

Table 1. Patients gender correlated with knee osteoarthritis grade.

\begin{tabular}{|l|c|c|c|c|c|}
\hline \multirow{2}{*}{ Gender } & \multicolumn{4}{|c|}{ Osteoarthritis Grade } & \multirow{2}{*}{ Total } \\
\cline { 2 - 5 } & I & II & III & IV & \\
\hline Male & 0 & $1(14.28)$ & $\begin{array}{c}2 \\
(28.57)\end{array}$ & $\begin{array}{c}4 \\
(57.14)\end{array}$ & \\
\hline Female & 4 & 10 & 12 & 14 & $40(100)$ \\
& $(10)$ & $(25)$ & $(30)$ & $(35)$ & \\
\hline Total & 4 & 11 & 14 & 18 & \\
\hline
\end{tabular}

Table 2. The mean values of serum cholesterol correlated with knee osteoarthritis grade.

\begin{tabular}{|l|c|c|c|c|c|}
\hline & I & II & III & IV & p \\
\hline Total cholesterol & 208 & $225.5 \pm$ & 223 & $208.9 \pm$ & \\
$(\mathrm{mg} / \mathrm{dL})$ & \pm 40.2 & 37.2 & \pm 56.1 & 64.2 & 0.44 \\
\hline Triglyceride (mg/dL) & 121 & $184.4 \pm$ & $109.6 \pm$ & $96.7 \pm$ & \\
& \pm 102.3 & 22.8 & 32.9 & 31.3 & 0.21 \\
\hline High Density & $46.3 \pm$ & $49.9 \pm$ & $53.1 \pm$ & $46.8 \pm$ & \\
Lipoprotein (mg/dL) & 10.6 & 13.3 & 13.6 & 9.6 & 0.61 \\
\hline Low Density & $153.8 \pm$ & $156.6 \pm$ & 153 & $132.2 \pm$ & \\
Lipoprotein (mg/dL) & 33.9 & 44.9 & \pm 53.2 & 46.4 & 0.91 \\
\hline
\end{tabular}

Statistic analysis with one way ANOVA shows there is no significant relationship between knee osteoarthritis grade and total cholesterol, trygliceride, HDL, LDL. 


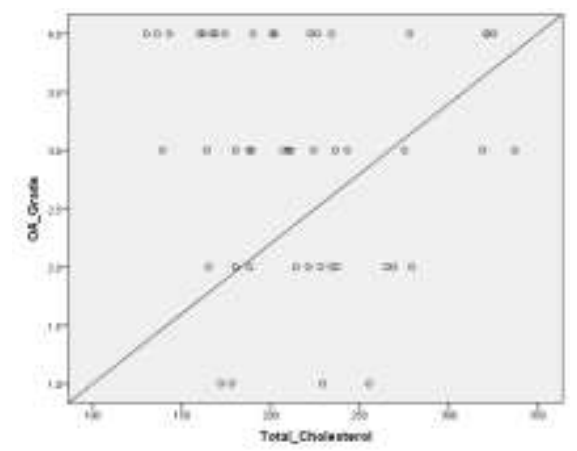

Figure 1. Scatter plot diagram shows the relationship of knee osteoarthritis and total cholesterol.

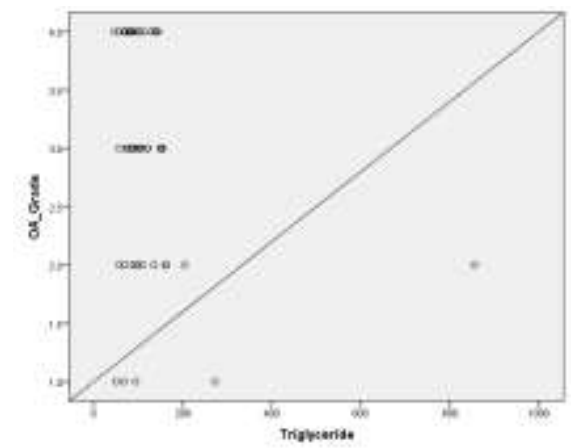

Figure 2. Scatter plot diagram shows the relationship of knee osteoarthritis and triglyceride.

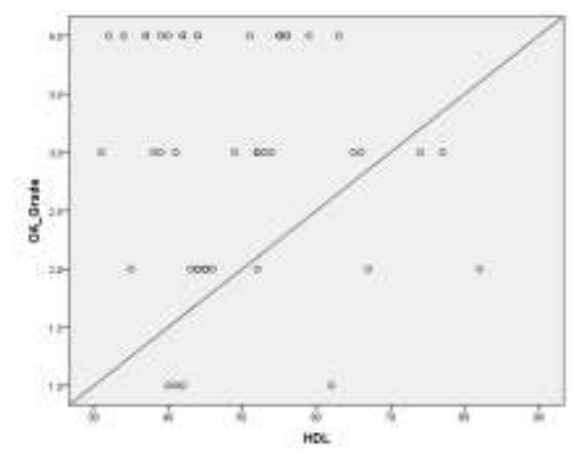

Figure 3. Scatter plot diagram shows the relationship of knee osteoarthritis and high density lipoprotein.

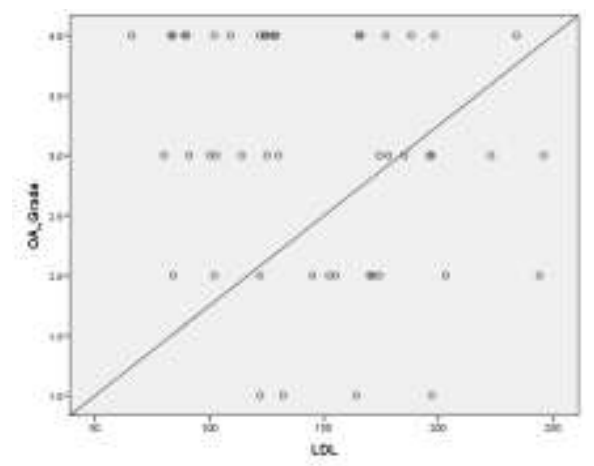

Figure 4. Scatter plot diagram shows the relationship of knee osteoarthritis and low density lipoprotein.

From figure 1 to 4 all of the scatter plot diagram shows no linear relationship between knee osteoarthritis grade and total cholesterol $(\mathrm{Y}=0.012 * \mathrm{x}+-0.2, \mathrm{r}=0.49)$, triglyceride $(\mathrm{Y}=0.003 * \mathrm{x}+1, \mathrm{r}=0.90)$, high density lipoprotein $(Y=0.05 * x+-0.5, r=0.92)$, low density lipoprotein $(Y=0.015 * x+0.25, r=0.66)$. 
Table 3. Statistic analysis between knee osteoarthritis grade and serum cholesterol.

\begin{tabular}{|l|c|}
\hline Serum cholesterol & p \\
\hline Total cholesterol & 0.486 \\
\hline Triglyceride & 0.898 \\
\hline High density lipoprotein & 0.902 \\
\hline Low density lipoprotein & 0.654 \\
\hline
\end{tabular}

Statistic analysis with Spearman Rho shows there is no significant relationship between knee osteoarthritis and serum cholesterol.

\section{Discussion}

The central purpose of this study was to evaluate the relationship between the knee osteoarthritis grade and serum cholesterol level without previous study about relationship between knee osteoarthritis and cholesterol. In this study, knee osteoarthritis grade were found have no association with total cholesterol, triglyceride, high density lipoprotein and low density lipoprotein, and after statistic analysis of the knee osteoarthritis and cholesterol, we also found there is no significant relationship between knee osteoarthritis and cholesterol.

Similiar findings have been reported in other studies. A longitudinal prospective study carried out by Bagge and colleagues showed an insignificant relationship between osteoarthritis and raised levels of cholesterol and triglycerides (Sturmer et al. 1998). Similiarly, Martin et al have found an insignificant association of hyperlipidemia and osteoarthritis and supported a stronger contribution of mechanical factors as opposed to systemic factors as opposed to systemic factors contributing in the pathogenesis of osteoarthritis (Martin et al. 1997).

There are studies have been reported contrary to this findings. Serum cholesterol levels were found to be significantly higher in the patients of generalized and knee osteoarthritis by Sturmer et al (Bagge, Bjelle, Eden \& Svanborg, 1991). In the Chingford study, Hart and coworkers investigated the relationship between the metabolic factors and knee osteoarthritis in the general population. Their analysis revealed that hypercholesterolemia was significantly correlated with unilateral and bilateral osteoarthritis after controlling for other confounding factors like obesity. However, their results did not reveal any significant association of triglycerides with osteoarthritis (Hart, Doyle \& Spector, 1995).

\section{Conclusion}

In conclusion, this is the first study to determine the relationship between knee osteoarthritis and serum cholesterol level with the result all the lipid and lipoprotein that observed in knee osteoarthritis radiograph have no relationship with osteoarthritis grade.

More study is needed to explain the aetiology and risk factors of osteoarthritis.

\section{Conflict of Interest}

No potential conflict of interest relevant to this article was reported.

\section{References}

1. Bagge E, Bjelle E, Eden S, Svanborg A. 1991. Factors associated with radiographic osteoarthritis: results from the population study 70 year old people in Goteborg. J Rheumatol 18:1218-22.

2. Clockaerts S. 2013. Role of infrapatellar fat pad in knee osteoarthritis lipid lowering drugs as potential therapeutic strategy. University of Antwerp.

3. Gabay C, Kushner I. 1999. Acute phase proteins and other systemic responses to inflammation. N Engl J Med 340:448-54. 
4. Hart DJ, Doyle DV, Spector TD. 1995. Association between metabolic factors and knee osteoarthritis in women. J Rheumatol 22:1118-23.

5. Martin K, Lethbridge CM, Muller DC, Elahi D, Andres R, Tobin JD, et al. 1997. Metabolic correlates of obesity and radiographic features of knee osteoarthritis; data from the Baltimore longitudinal study of aging. J Rheumatol 24:702-7.

6. Mutiwara et al. 2016. Hubungan indeks massa tubuh dengan derajat kerusakan sendi pada pasien osteoarthritis di RSUP Dr. M. Djamil Padang. Jurnal Kesehatan Andalas 5(2).

7. Qureshi KI, Afzal M.N. 2014. Comparison of serum lipid levels among patients suffering from osteoarthritis in Pakistan. Rawal Medical Journal No. 1, January - March.

8. Stone NJ. 1994. Secondary causes of hyperlipidemia. Med Clin North Am 78:117-41.

9. Sturmer T, Sun Y, Sauverland S, Zeissing I, Gunther KP, Puhi W, et al. 1998. Serum cholesterol and osteoarthritis. The baseline examination of the Ulm osteoarthritis study. J Rheumatol 25:1827-32. 